\title{
Ruy Belo é o ensaísta vivo que me interessa mais
}

Luis Maffei

Universidade Federal Fluminense

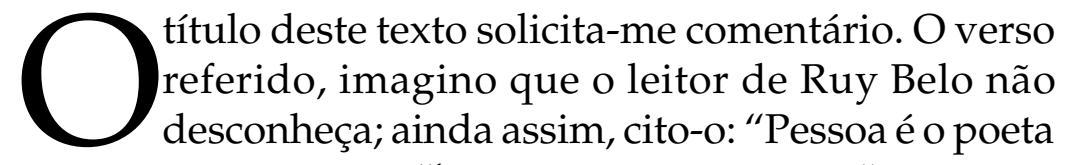
vivo que me interessa mais"1. Em 1969, ano em que "Da poesia que posso" veio à luz dentro de Homem de palavra(s), Pessoa estava tão vivo como a necessidade de tê-lo como interlocutor. O verso possui muita legibilidade e muitas legibilidades, uma das quais dar a ver que Pessoa, poeta de interesse, é poeta de inter(dentro ou entre) esse (ser): estou num entre com Pessoa, estou em Pessoa, "poeta vivo", tão meu contemporâneo como El Cid: "Só depois é que pergunto que fazer de tudo isto / que torna o cid meu contemporâneo" ${ }^{\prime 2}$. Ruy Belo é o ensaísta vivo que me interessa mais porque é meu contemporâneo, escreve da poesia que pode, posso, podemos, bem a meu lado, enquanto eu o leio e medito sobre a poesia de nosso tempo, sobre poesia. Remonta a certa modernidade o que em Ruy Belo se pode chamar de ética, mas é o próprio quem, diante da pergunta "Acha que o papel da poesia se tem transformado?", responde, em entrevista ainda nos anos de 1960: “De um modo geral, penso que não. A poesia

\footnotetext{
${ }^{1}$ BELO, 2004a, p. 337.

${ }^{2}$ BELO, 2004a, p. 337.
} 
é a mesma neste e naquele lugar, através dos tempos", pois é sempre "aventura de linguagem"3.

O ano de 1961, quando Aquele grande rio Eufrates veio ao mundo, também assistiu a Jorge de Sena reunir sua obra até então editada em Poesia - I. O famoso prefácio do volume diz que "à poesia, melhor que a qualquer outra forma de comunicação, cabe, mais que compreender o mundo, transformá-lo" ${ }^{\prime 4}$. Sena é nome importante para a construção da beliana ética em poesia. Anos depois de 1961, Ruy Belo e Jorge de Sena, em triste coincidência, deixariam este mundo no mesmo 1978. O mais jovem disse que "a palavra poética é a primeira"5, ainda que não tenha sido o primeiro a dizê-lo. Uma permanência romântica na alta modernidade orienta esse dizer, e volto ao título de meu texto: Ruy Belo, vivo, é o ensaísta que me interessa mais pois dentro de suas reflexões, ou entre suas reflexões, acho lugar pródigo para assuntos de poesia, e adiro ao que o poeta pensa, aprendo com ele. A poesia muitas vezes me vem por Ruy Belo, escrevo graças a poetas como Ruy Belo, por cuja reflexão ensaiada em versos ou fora deles a poesia se mostra como aprecio vê-la, vivê-la.

Não é apenas como leitor de poesia que digo esta reflexão, mas também como poeta que habita específicos lugar, tempo e idioma. $\mathrm{O}$ autor de Boca bilingüe me diz que a palavra poética é "filha do tempo", e, "no entanto, tem de vencer o tempo"6. Antes de qualquer coisa, a palavra poética é filha de Cronos, e por ele é devorada. Mas, como filha rebelde e indócil, luta por permanência e leitores futuros, o que encerra combate, no fundo, por uma condição de sobrevida em estado de contemporaneidade, o mesmo de Pessoa e Cid para Ruy Belo, o

\footnotetext{
${ }^{3}$ BELO, 2002, p. 24.

${ }^{4}$ SENA, 1961, p. 11.

${ }^{5}$ BELO, 2002, p. 69.

${ }^{6}$ BELO, 2002, p. 69.
} 
mesmo de Ruy Belo para mim, para nós. Segundo Agamben,em já consagrado (penso que pelas melhores razões), ainda que recente ensaio, "contemporâneo é aquele que mantém fixo o olhar no seu tempo, para nele perceber não as luzes, mas o escuro"7. Ruy Belo ajuda-me a perceber melhor, em nosso tempo, o escuro, que se choca com um excesso de claridades duvidosas. Iumna Simon comenta, em artigo recente, certa recorrência da poesia brasileira de agora:

Quem vem depois acredita que, pelas graças da diacronia, herda automaticamente tudo o que veio antes. Situa-se num momento adiantado, não precisa prestar contas, não se impõe uma disciplina criadora ou expressiva, nem pretende formular um projeto - ideia considerada autoritária e canônica, de uma verdade única (...). ${ }^{8}$

A autora parte de dois casos específicos que, a seu ver, revelam uma faceta perigosa e perigosamente majoritária da poesia brasileira contemporânea. Não quero, neste espaço, discutir as obras dos autores comentados por Iumna, tampouco me colar demasiado à perspectiva da autora. Não quero, tampouco, o contrário disso, posto que enxergo a reação agressiva que esse ensaio sofreu como uma ação, menos que propositiva de um debate, brasileiramente corporativista, além de indicativa do incômodo que uma fala dissidente pode causar nos dias de hoje a certos olhos dados a contentamentos unânimes.Mas o que agarro, em Iumna, é "projeto", palavra querida pelos românticos, aceita pelos modernos, estranha para nosso tempo fluido em demasia, por vezes político de menos. Há tempos, assisti a certa conversa entre escritores que chegou

\footnotetext{
${ }^{7}$ AGAMBEN, 2009, p. 62.

${ }^{8}$ SIMON, 2011, p. 84.
} 
à indefectível discussão sobre o papel da internet em assuntos literários. Ouvindo o que foi dito e pensando no que seja, contemporaneamente, a ideia de projeto, assusta-me concluir que o comprometimento médio da literatura produzida atualmente passa pela construção de um leitor muito especificamente possível e, como se não bastasse, por mais aceitação obediente que recusas.

Em outras palavras: a citada mesa-redonda centrou-se num problema que indica a nossa pouca vontade de abrir portas, mesmo que as tenhamos de arrombar docemente. Outro exemplo triste: a discussão mais acalorada que 2013 testemunhou no universo editorial no Brasil teve que ver com autorização prévia ou não para biografias. Alguns dos protagonistas da rumorosa contenda foram Caetano Veloso e Roberto Carlos. Não é preciso dizer que ninguém perguntou publicamente a quem interessa discutir biografias num país que já não sabe diferençar, com base em conteúdos, livros de livros. Tampouco se problematizou o esvaziamento da ficção e o predomínio mercadológico de textos biográficos, nem a atenção a figuras de teoria nenhuma como os dois cantores populares acima nomeados.

Algo muito distinto do que foi dito na mesa-redonda e do que tem sido dito por aí disse Ruy Belo, em entrevista já citada, na resposta à questão "Que papel atribui à poesia no mundo de hoje?" - a propósito, nas discussões hodiernas sobre livro, literatura e mercado no Brasil, a palavra poesia é tão ouvida quanto runjebe ou caajuçara -:

O poeta é homem e por vezes indigna-se com o que vê. Daí a revolta. Mas nem toda a revolta é poesia. O poeta deve cantar a vida, apesar de a vida humana ser uma loucura. (...). O poeta, através da poesia, pode vir a conhecer-se melhor e ajudar os outros a conhecer-se. A poesia deve servir a um 
ideal de comunhão humana. Ou não deve servir nada disto, mas sim ser fiel a si própria, que é ser poesia. ${ }^{9}$

Poesia por Ruy Belo é compromisso, ou fidelidade, vocábulo caro a Jorge de Sena. Poesia por Ruy Belo é atenção extrema ao que cerca o poeta, e não olho vivo à confraria de leitores que leem os belos versos e abraçam a iluminada figura que os compôs: essa contentinha, portanto lamentável, figura é ridicularizada, pela desestabilizante ironia, em poemas como "Emprego e desemprego do poeta", que se refere a "um poeta em exercício" que chega "mesmo a fazer versos a pedido"10: de quem? De quê? Por Ruy Belo, poesia é o próprio possível - aprendo-o com o poeta, aprendendo também que o melhor possível é o que se dá à invenção, não ao pelo menos. Já referi “Da poesia que posso", refiro agora um título central, País possível. De acordo com a "Nota do autor" na abertura do volume, "poesia comunica (...) desde que se faça o leitor chegar até ela, esse leitor saído talvez de um povo que hoje, em Portugal," se encontra em "estado de alienação ou alheamento" ${ }^{11}$ de sua própria cultura.

Segue o poeta: "País possível" é, "mais do que uma antologia, um livro novo: o livro possível"12. Poderia citar mais, o parágrafo merece. Parei onde parei porque a ideia de "possível" para o poeta desse país é importante: com efeito, não me é lisamente dado meu país, eu o desenho - a nota que abre o livro é datada de 1 de maio de 1973, e localizada em Madri. Não há, pois, um óbvio país, é tarefa do poeta possibilitá-lo, torná-lo real, poeticamente possível. "O Portugal futuro" não se encontra

\footnotetext{
9 BELO, 2002, p. 23.

${ }^{10}$ BELO, 2004a, p. 29.

${ }^{11}$ BELO, 2004b, p. 140.

${ }^{12}$ BELO, 2004b, p. 140.
} 
apenas em Homem de palavra(s), mas também em País possivel, posto que "podia ser duro/ edificar" "o portugal futuro" ao som das "horas do relógio da matriz"13, pois "isso era o passado". A rima me captura: a reiteração dos sons em "duro" e "futuro" me indica um porvir duradouro? Ou um futuro duro como a abóbada descrita por Herculano? Ou, pelo contrário, uma tarefa tão dura que de difícil realização?

O que há, indiscutivelmente, é "projeto", coisa, de acordo com Iumna Simon, mal querida por muitos poetas brasileiros de agora, por ser "considerada autoritária e canônica, de uma verdade única". Quem pensa assim não percebe o que Ruy Belo sempre percebeu: há uma enorme, abismal diferença entre projeto e prescrição. Projeto é apontamento que parte de alguma ética, algum valor, ao futuro, enquanto prescrição é imposição de modelo. A recusa do projeto não seria, agora sim, uma prescrição? De acordo com o poeta possível, "A poesia deve servir a um ideal de comunhão humana. Ou não deve servir nada disto, mas sim ser fiel a si própria, que é ser poesia", ou seja, há um jogo a ser jogado, que não é unívoco nem inequívoco, e projeto é coisa que gosta de se lançar ao devir.

Por quê? Porque "Poesia é complicação, é doença da linguagem, é desvio da sua principal função, que será comunicar. Só o poeta se fica na linguagem, os outros passam por ela, servem-se dela"14. Fidelidade à linguagem, comprometimento com a subversão da linguagem. É assim que a "poesia comunica (...) desde que se faça o leitor chegar até ela". Que leitor? "Poesia e educação" e "Da espontaneidade em poesia" são dois dos ensaios belianos que mais me ajudam a pensar o poético. Se escrevo como leitor de poesia e poeta, escrevo também como professor de literatura, incapaz de ensinar alguém a escrever versos, capaz de tentar que o outro seja um leitor possível -a leitura de poesia exige um tipo muito ousado de educação.

${ }_{13}^{13}$ BELO, 2004b, p. 147.

${ }^{14}$ BELO, 2002, p. 108. 
Nos dias de hoje, o leitor que muitos autores vicejantes ambicionam é o que se deixa seduzir pelo contrário da exigência, ou, no sentido da velha e necessária coautoria de quem lê, do trabalho. Não interessa ao poeta do possível, leio em "Da espontaneidade em poesia", "o poema acessível, directo, chato, incapaz da menor invenção" ${ }^{\prime 15}$, pois este não assume qualquer comprometimento com o labor parceiro que vivem texto e leitor. Muitos cursos que ministrei até hoje começaram com uma discussão acerca da assertiva presente em "Da espontaneidade em poesia" que fala de complicação, pois não apenas aprendo com as reflexões de Ruy Belo, mas busco, com elas, algum ensinamento ao outro: é preciso que jovens leitores tenham em mente a "complicação" e a "doença" que a poesia é, e o "desvio" que ela promove.

Complicação: oposto, não de simplicidade, mas de retilineidade e amansamento, posto que o caminho da poesia é curvo e está necessariamente para além dos limites de nossos olhos - por isso a poesia nos força a vencer nossos antolhos; doença: páthos, relação com a língua em estado de perda, tanto no camoniano sentido da perdição amorosa - "Amor é" "um cuidar que ganha em se perder"16-, como na impossibilidade, que o genuíno poeta reconhece, de tudo poder ser dito, e por isso Ruy Belo confessa que "Poetar é, no fundo, mais um acto de humildade"17; desvio: curva, hipótese radical de superação do privilégio do referente. Em poesia, o signo é posto em exploração profunda, e se encontra forçado à ameaçadora condição da multivalência.

A poesia, quando comprometida com um projeto, não é necessariamente prescritiva - a não ser que se dobre a

${ }^{15}$ BELO, 2002, p. 108.

${ }^{16}$ CAMÕES, 2005, p. 119.

${ }^{17}$ BELO, 2002, p. 85. 
finalidades imediatas, num entendimento tacanho de projeto ${ }^{18}$; neste caso, não merece sequer, por Ruy Belo, o nome de poesia. É importante repetir: “A poesia deve servir a um ideal de comunhão humana. Ou não deve servir nada disto, mas sim ser fiel a si própria, que é ser poesia". Que seja o poema possível, dotado de poder? O que possui, diz o ensaísta vivo que me interessa mais, "capacidade de surpreender num ápice, de provocar esse delicioso traumatismo que é a emoção estética. Se há uma poesia moderna é a poesia da surpresa, da aventura, do rigor" ${ }^{\prime 19}$. Jorge de Sena chamou moderno a Sá de Miranda. A modernidade beliana tem muito que ver com o século XX; não obstante, "rigor" é conquista mirandina, camoniana, etc.

${ }^{18}$ Pensar nisto em texto sobre Ruy Belo obriga-me a ter em mente a recente edição brasileira da obra beliana, livro por livro. Imagino que não por oportunismo, mas num opcional descuido à brasileira, o organizador da série convidou, para cada um dos prefácios, poetas brasileiros, não ensaístas, acreditando na máxima de que poeta lê poesia melhor que ninguém. Isso é uma falácia, não porque poetas não sejam bons leitores de poesia, mas porque há muitos ensaístas, não necessariamente também poetas, que leem poesia de maneira primorosa, além de teoricamente embasada e pensada. A escolha do referido organizador é desrespeitosa a professores de literatura que leem Ruy Belo há tempos com seriedade e ensaísmo lúcido e criativo, de que são exemplo os nomes de Jorge Fernandes da Silveira e Ida Alves. Além disso, em virtude de os convidados serem majoritariamente pertencentes a uma mesma turma, não houve sequer o cuidado de providenciar ao leitor brasileiro, desconhecedor da poesia de Ruy Belo, apresentações que tornassem bem acompanhada a primeira leitura, bastando, para a escolha do prefaciador, ser amigo e fazedor de versos; se o ensaísmo de tal indivíduo permite ou não eficaz apresentação do poeta, não parece importar. Ironia: tenho de falar disso escrevendo precisamente sobre o ensaísmo de Ruy Belo... ${ }^{19}$ BELO, 2002, p. 108. 
Certa expressão recém-citada, "delicioso traumatismo", põe-me muito atento: a ação da poesia não descarta alguma violência. Nesse ponto, e também no que tange ao possível no sentido de poder, Ruy Belo e Herberto Helder se afinam - 0 poeta que em 1961 lançou $A$ colher na boca é homenageado no famosíssimo "Vat 69": "era depois da morte Herberto Helder"20. O projeto herbertiano bem poderia ter como tabuleta o verso "- Uma frase, uma ferida, uma vida selada" ${ }^{21}$, de Última ciência. Deliciosa frase ferida, marcada por uma vida de leitura dos sentidos desviantes, complicados e doentes, ou seja, apaixonados; delicioso trauma, rigor e "emoção estética".

Emoção ética? Aristóteles entende ética como a procura do bem. A que tipo de bem, ou de justiça, a poesia pode levar? Em famosa carta, Kafka escreveu que não precisamos de livros que nos conduzam à felicidade, mas "de livros que nos atinjam como o pior dos infortúnios (...), que nos façam sentir como se tivéssemos sido banidos para a floresta (...)". Por isso, “Um livro tem de ser um machado para o mar gelado de dentro de nós"22. O que o autor de $O$ processo pensa com livro, pensarei com poesia, coisa que ocupa livros: alguns poemas parecemme ter mesmo a chave do "mar gelado de dentro de nós", ou seja, daquilo que em cada um dos humanos é indivisível e excessivamente solitário. Essa chave, para dizer de novo com Herberto Helder, "não abre quase coisa alguma", abre "um espaço em cada nome". Aí, nesse espaço novo, aberto, podemos criar encontros de indivisibilidades, que não deixam de ser indivisíveis mas se podem afetuosamente comunicar.

Talvez apenas na floresta, ou nas profundezas de nosso gelado mar interno, cheios de um doloroso trauma, possamos perceber o que seja "emoção estética": etimologicamente,

${ }^{20}$ BELO, 2004a, p. 295.

${ }^{21}$ HELDER, 2009, p. 438.

${ }^{22}$ Apud MANGUEL, 1997, p. 113 
estético é o que causa sensação, enquanto seu contrário é o anestésico. Aí reside, penso por Ruy Belo, Sena, Camões e poucos outros, a ética do poema, posto que faz sentir. Em "Poesia e educação", afirma quem apreciava estar $\mathrm{Na}$ senda da poesia: "Ensinam-nos Os Lusíadas mas, em vez de se valorizar o que neles há de poético, põe-se em relevo o que é acidental e extraem-se lições que não decorrem imediatamente da sua $a^{\prime \prime 2}{ }^{\prime 23}$. Ou da sua ética, pois sua ética é sua arte, não apenas $o$ primor dos decassílabos, mas surpreendentes sentidos que decorrem, por exemplo, de certas rimas. Os versos finais da estância 120 do Canto III são célebres: "Aos montes insinando e às ervinhas / O nome que no peito escrito tinhas." ${ }^{24}$, Inês.

O que aí é irredutivelmente poético? O fato de a masculinidade do capitão ser usada num discurso de ética defensora do feminino, algo deveras camoniano - a reler "[Um mover d'olhos brando e piadoso]" e "[Aquela cativa]" -: é Vasco da Gama quem usa o diminutivo para referir um elemento natural, "ervinhas", com o qual rima o verbo da posse, agora perdida, ter, "tinhas". Somente um leitor capaz de ler poderá ler os desdobramentos de sentido que versos como esses possibilitam. Deleuze e Guattari consideram que a obra de arte é um "composto de perceptos e afectos" 25 , que vão além das meras percepção e afecção. Em quem? Em quem se encontra diante da obra, ou melhor, junto com a obra, disposto a lidar com ela. No caso da poesia, a estética tem uma aguda peculiaridade, pois possui "complicação", "doença" e "desvio". De todas as linguagens artísticas, a poesia é decerto a mais trabalhosa e a menos imediatamente compensatória, pois a delícia que proporciona não se dá à primeira vista. O texto poético ameaça o já nada seguro instrumento que nos compõe, e que, por isso, simula ter alta segurança: a língua.

${ }^{23}$ BELO, 2002, p. 105.

${ }^{24}$ Lus, III, 120, 7-8.

${ }^{25}$ DELEUZE \& GUATARRI, 1997, p. 213. 
Texto de jouissance, segundo Roland Barthes: "aquele que põe em estado de perda, aquele que desconforta (...), faz vacilar as bases históricas, culturais, psicológicas do leitor, a consistência de seus gostos, de seus valores e de suas lembranças, faz entrar em crise sua relação com a linguagem"26. Gozar exige aprendizagem, pois exige arte e engenho. Nessa estética desestabilizadora, nesse fazer sentir, nessa superação do anestésico reside a inexorabilidade ética da poesia. $\mathrm{Ou}$, como leio em "Poesia e luta pelo poder", “(...) ao poeta compete dizer firmemente que não, tornar suas as preocupações dos outros homens, emprestar voz àqueles que por qualquer razão a não tenham, sejam eles pessoas, árvores, pedras ou simplesmente a terra, essa terra dos homens" ${ }^{27}$.

Representação, projeto, ética, política e nenhuma concessão ao poema imediatista, abdicador da "aventura de linguagem", pois só no deslocamento que a poesia acessa enquanto plena potência em movimento é possível que tenha lugar a representação - do outro, da cena, do drama. O poeta cria, resiste, diz "não" e torna crítica a relação do leitor com a linguagem, espaço coletivo, lugar comum que, revolvido, se torna espaço de "perceptos e afectos" - por assim dizer, o que o bom leitor "sente 'stá pensando" 28 , e não há como Pessoa deixar de ser demasiadamente vivo.

Chego só agora a um dos textos sem versos mais importantes de Ruy Belo: o prefácio a Transporte no tempo, de 1973, "Breve programa para uma iniciação ao canto": "A poesia é um acto de insubordinação a todos os níveis, desde o nível da linguagem como instrumento de comunicação, até ao nível do conformismo, da conivência com a ordem, qualquer

${ }^{26}$ BELO, 2004, p. 21.

${ }^{27}$ BELO, 2002, p. 311.

${ }^{28}$ PESSOA, 1993, p. 99. 
ordem estabelecida" 29 . A linguagem que tão somente comunica não se afasta da arbitrariedade do signo linguístico revelada por Saussure, e nisso reside um poder opressor, imobilizador - o fascismo dito por Barthes, quiçá, que nos obriga, animais linguísticos, à tagarelice. "Por outro lado", afirma Jean-Luc Nancy, "o que resiste com a poesia (...) é o que, na língua ou da língua, anuncia ou contém mais do que a língua" ${ }^{30}$. Sim, insubordinação, e a poesia terá uma vocação revolucionária. Nesse sentido, ela própria é uma ética.

Por Ruy Belo, não há "ordem estabelecida" com que a poesia se possa aliançar. "Breve programa para uma iniciação ao canto" foi escrito nos estertores do fascismo em Portugal, mas o poeta é claro ao apontar para "qualquer ordem". O que provocou Iumna Simon a escrever seu citado texto é também uma "ordem estabelecida", desapreciadora do debate e afim a um imobilismo em nada poético. No texto de Transporte no tempo, leio ainda: "Escrever é desconcertar, perturbar e, em certa medida, agredir". Mas todo poeta age assim em nossa língua, em nossos países? Nós, poetas, de fato percebemos nossa dimensão insubmissa, insubornável? "É claro", segue o prefácio, "que falo do poeta, e não do poetastro, do industrial e comerciante de poemas, do promotor de vendas das palavras que proferiu" (2004b, p. 10) ${ }^{31}$. Em nosso mundo, poucos dão atenção à poesia. Mas nos vários mundinhos ocupados por gente às voltas com poesia, ou algo assim, há prestígios internos e umbigos minoritários em jogo. Ruy Belo ajuda-me muito a refletir sobre isso, e por essas e outras um texto como o de Iumna chama tanto a minha atenção.

Respondi, certa vez, um inquérito promovido pela revista pequena morte,cuja provocação era a famosa sentença de Wilde:

\footnotetext{
${ }^{29}$ BELO, 2004b, p. 9.

${ }^{30}$ NANCY, 2005, p. 36.

${ }^{31}$ BELO, 2004b, p. 10
} 
"Um livro não é, de modo algum, moral ou imoral. Os livros são bem ou mal escritos. Eis tudo". Leitor de Ruy Belo, aprendiz de poesia por Ruy Belo, forjei, para indicar a abundância de mercadores literários em nossa época, hábeis praticantes de uma moral oportunista - por vezes aparentemente amoral ou transgressora -, a expressão "lógica do camelô": nada pode ser tão diferente de ideias como as belianas. A propósito, os praticantes da "lógica do camelô" muitas vezes ignoram a existência de "camelôs de verdade" ${ }^{\prime 32}$. Esses últimos interessam a Ruy Belo, e não ao "poetastro", ao "comerciante", ao "promotor de vendas" do que não é vendável, e, se o for, já estará vendido. O futuro do poeta terá de ser sua morte, quando repousará "finalmente tranquilo, finalmente pacífico, (...), finalmente senhor e súbdito do silêncio que em vão tentou aprender com as palavras" ${ }^{\prime 3}$.

Bela lição poética, a morte. Não apenas, e não exatamente, o desaparecimento de um indivíduo, mas a coragem para a formulação de seu desaparecimento. "Poetar é, no fundo, mais um acto de humildade", poetar é, no fundo, um ato de coragem. Quando não, faz barulho demais, poesia de menos. Prefiro a poesia por Ruy Belo, o ensaísta vivo que me interessa mais por dramática e insubmissamente poeta.

\section{Referências bibliográficas}

AGAMBEN, Giorgio. O que é contemporâneo? e outros ensaios. Tradução de Vinícius Nicastro Honesko. Chapecó: Argos, 2009.

BARTHES, Roland. O prazer do texto. 4. ed. Tradução de J.. Guinsburg. São Paulo: Perspectiva, 2004.

BELO, Ruy. Na senda da poesia. Organização Maria Jorge Vilar de

${ }^{32}$ MAFFEI, 2009.

${ }^{33}$ BELO, 2004b, p. 12. 
Figueiredo. Lisboa: Assírio \& Alvim, 2002. . Todos os poemas I. 2. ed. Lisboa: Assírio \& Alvim, 2004a. . Todos os poemas II. 2. ed. Lisboa: Assírio \& Alvim, 2004b.

CAMÕES, Luís de. Os Lusíadas. Edição organizada por Emanuel Paulo Ramos. Porto: Porto editora, 1978.

. Rimas. Texto estabelecido e prefaciado por Álvaro J. da Costa Pimpão. Coimbra: Almedina, 2005.

DELEUZE, Gilles \& GUATTARI, Félix. O que é a filosofia?. 2. ed. Tradução de Bento Prado Jr. e Alberto Alonso Muñoz. Rio de Janeiro: 34, 1997.

HELDER, Herberto. Ofício cantante - poesia completa. Lisboa: Assírio \& Alvim, 2009.

MAFFEI, Luis. Resposta ao inquérito "Como falar da moralidade dos livros? - comentários a uma provocação de Wilde". Revista pequena morte 17. http://pequenamorte.com/2009/06/24/como-falar-da-imoralidadedos-livros-comentarios-a-uma-provocacao-de-wilde/.

MANGUEL, Alberto. Uma história da leitura. São Paulo: Companhia das Letras, 1997.

NANCY, Jean-Luc. Resistência da poesia. Tradução de Bruno Duarte. Lisboa: Vendaval, 2005.

PESSOA, Fernando. O Eu profundo e os outros eus. Seleção de Afrânio Coutinho, fixação dos textos e notas por Maria Aliete Galhoz. 22. ed. Rio de Janeiro: Nova Fronteira, 1993.

SENA, Jorge de. Estudos de literatura portuguesa I. Lisboa: Edições 70, 1989.

. Poesia - I. Lisboa: Moraes, 1961.

SIMON, Iumna Maria. Condenados à tradição - o que fizeram com a poesia brasileira. Revista Piauí 61. Outubro de 2011. p. 82-86. 


\section{Resumo}

Ruy Belo, além de poeta notável, exerceu intensa atividade ensaística. Pensando atentamente a poesia, e tendo a ética como baliza, Ruy Belo deixou um precioso legado para o estudioso de literatura em geral, pois sua maneira de refletir sobre poesia contempla, desde traços constitutivos da estrutura poemática, até aspectos históricos, articulando uns e outros, e diversos além desses. Ler hoje o ensaísmo de Ruy Belo é convite para entender a poesia como atividade revolucionária e rebelde.

\section{Abstract}

RuyBelo was aremarkablepoet, but also anessayistwith intenseactivity.Thinkingcarefullypoetry, and havingethics as abeacon,RuyBeloleave aprecious legacytothe student ofliterature in general, because their wayof thinking aboutpoetrycontemplatesconstitutive traitsofpoetic structure and historical aspects, articulating one anotherandmanybesides these. Today,RuyBelo's essayism is aninvitation to understandpoetry asrevolutionaryand rebelliousactivity. 
